\title{
TEARS OF BLOOD AND RAIN \$ USD IN INDONESIA (Covid19 Case Study 2020-2021)
}

\author{
By : \\ ENDANG NARYONO \\ LECTURER OF STIE PASIM SUKABUMI
}

Humans can only try but God is the one who decides, when the government is full of optimism with economic growth which since 2016 - 2019 has been sharply corrected not in line with expectations, although many doubt it because it is too dreaming in the midst of the world's economic downturn and macro and micro indicators that are not supportive. At the end of 2019 the world was shocked by a humanitarian disaster, namely Covid-19 which started from Wuhan, China and spread throughout the world. Many observers say that Covid19 has spread to Indonesia but the government denies it and many ministers underestimate it and even make it a very unfunny joke.

It was only on March 2, 2020 that the government announced that Covid19 had entered Indonesia. The government began to panic especially the people, people stormed shopping centers so that basic commodities became scarce even if they were available, the prices were very expensive, health products disappeared from the market because there were many inappropriate purchases and many people hoarded them in the hope of getting high profits. The government seems to be in a dilemma between the economy or the safety of its people, both of which are very important, especially since Indonesia's economic growth is largely influenced by public consumption.

Now that we have entered the second year of Covid19, there are no signs that mean that covid19 will disappear in the world and especially in Indonesia on June 10-16, 2021, the surge affected by Covid19 is getting crazier, even as if it is out of control at the athlete's house in Jakarta, the occupancy is approaching $80 \%$. has exceeded the limits set by the WHO, West Java, Central Java and East Java. The higher spike makes people more nervous and makes it more difficult to survive.

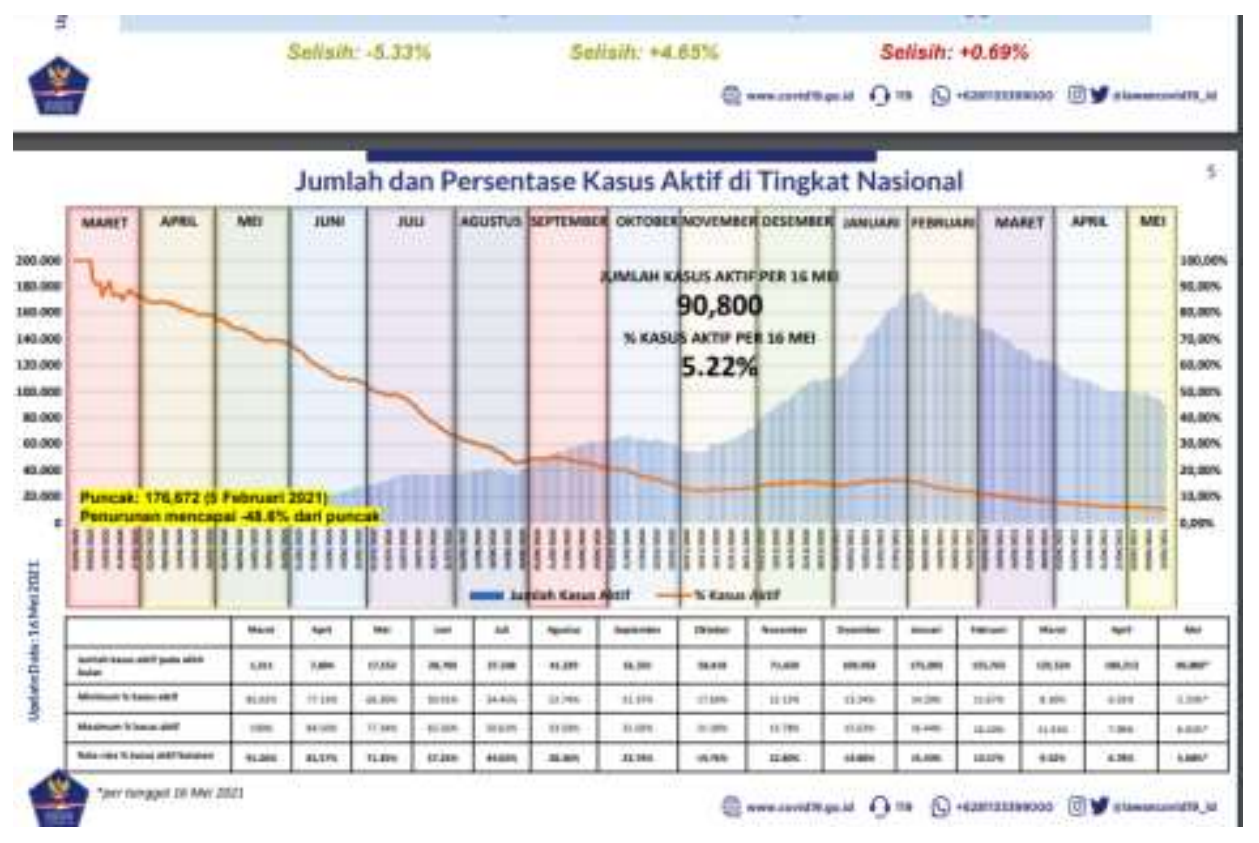


Source: Covid19 Task Force of the Republic of Indonesia 2021

Tens of thousands of people have died, hundreds of thousands of children have been orphaned and millions of people have lost their jobs. At present the government is in the form of making policies so that economic interests and health can go hand in hand because if you choose one country you will not be able to bear it, it seems like a two-legged policy but what are you doing in the midst of a widening budget deficit above 3.5\%, not to mention an increasingly fiscal burden The pressure made the government look for the best solution to keep the economy running.

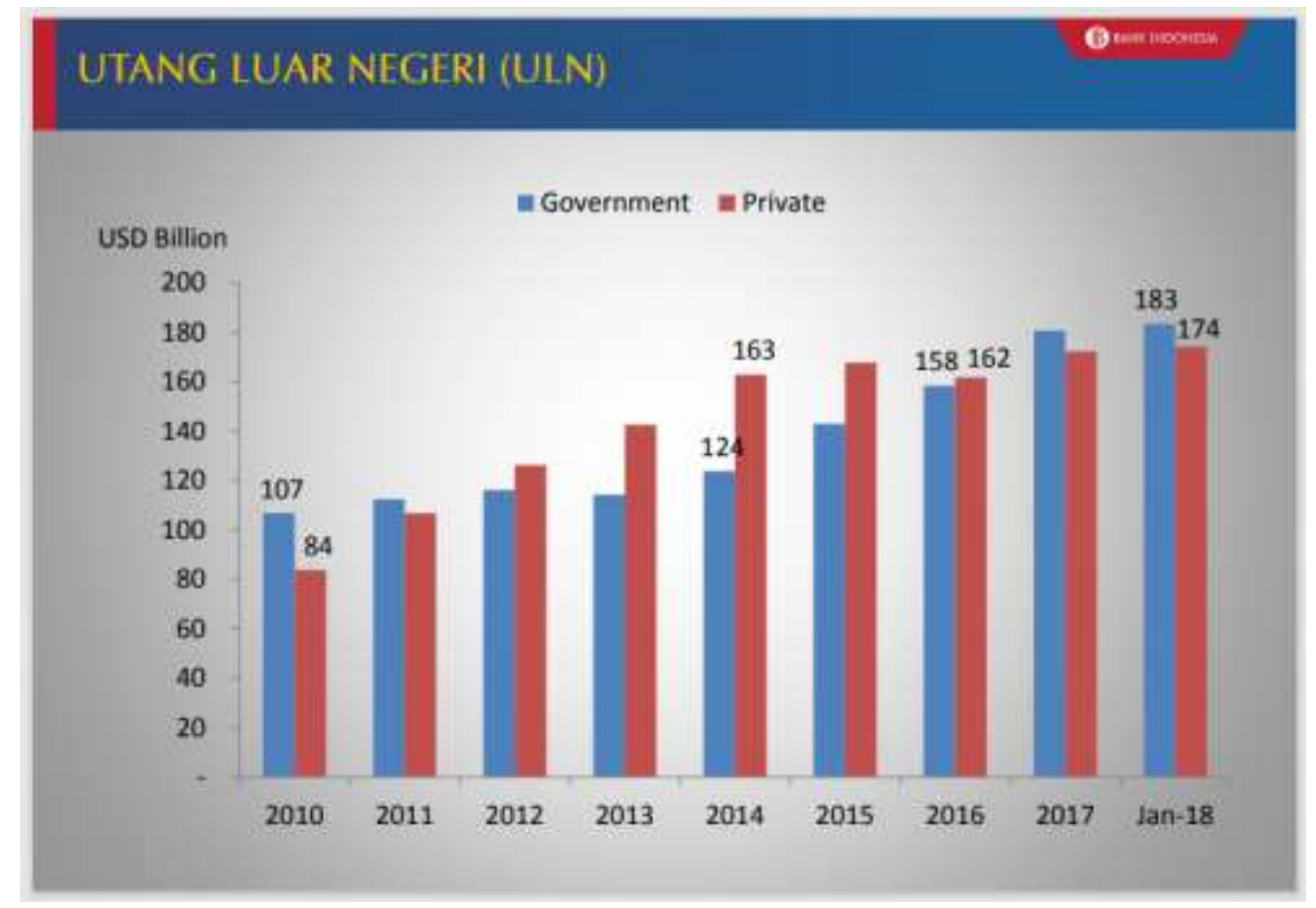

Source: Bank Indonesia Year 2020

The solution to borrowing money is through foreign debt but it becomes a simalakama, during which 7 years the growth of foreign debt has increased very rapidly, especially to cover the APBN which has widened the deficit at 3.5\% of GDP. Indeed, the government needs large liquidity to drive development, but if development is financed from debt, it will burden the fiscal, especially when short-term debt is used for long-term investment, so that in the long term, interest and principal installments will be charged.

The pressure on the fiscal so far has limited fiscal movement because it is burdened by the burden of principal installments and interest on maturing debt. Indeed, the main objective of Indonesia's debt is to cover the widening budget deficit so that development can continue and move the real sector. It's just that if forest management is not careful, it will have a very risky impact on countries that fail to pay their foreign debts. And if this happens, it will have a bad impact on Indonesia in the eyes of the world. 


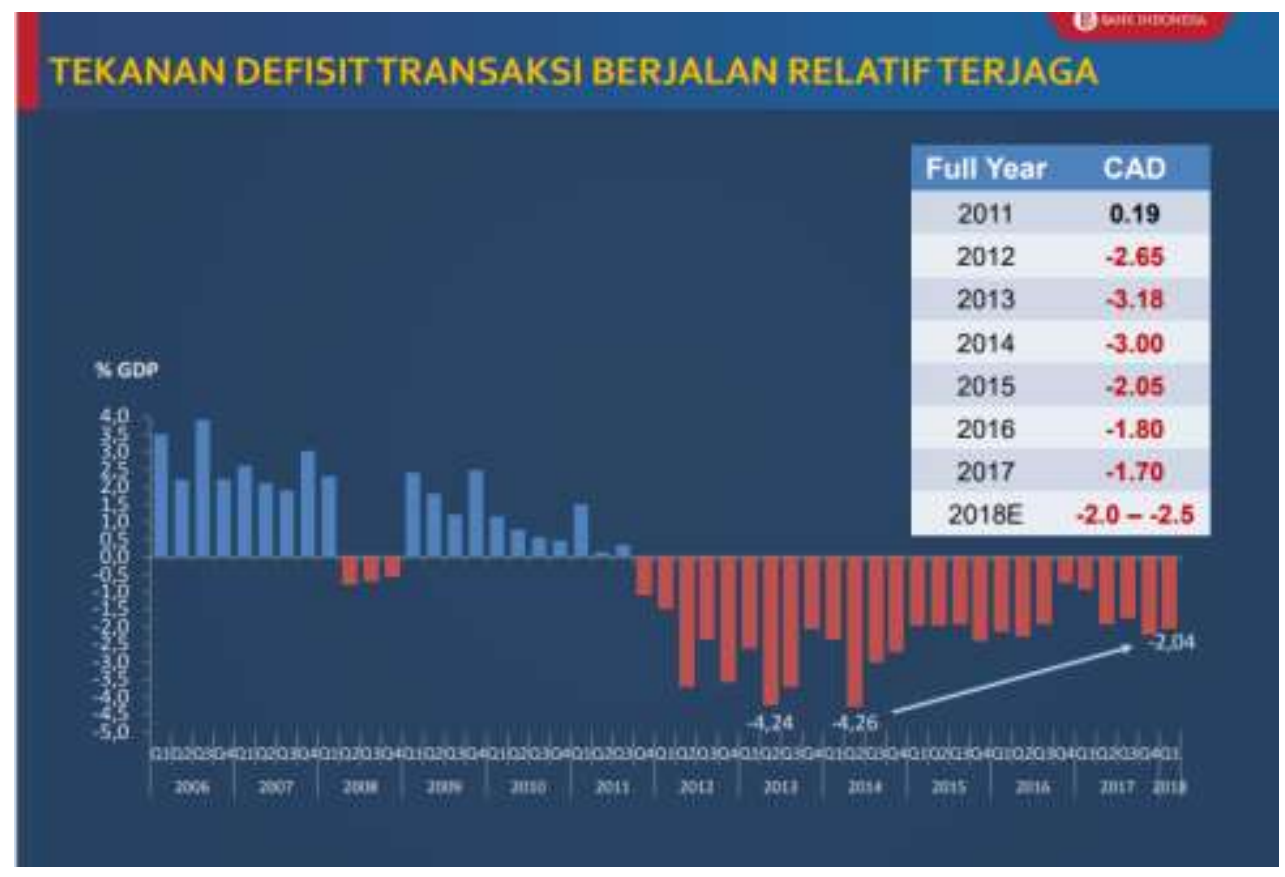

Source: Bank Indonesia Year 2019

The policy for these two years amid the Covid-19 outbreak has not shown macro and micro economic indicators to grow, so the threat of a budget deficit for the 2022/2023 fiscal year will widen, even though the government through the finance department will submit a law regarding the tax on staples that has been submitted to the DPR but Seeing the current situation in the midst of people's difficulties with low purchasing power, of course it will burden the community even more. Especially the lower middle class.

The humanitarian disaster that has occurred over the past two years seems to have shattered the foundations of the nation and state. The existence of the country in the midst of these multidimensional difficulties has been questioned by some people, this is because the policies taken seem half-hearted and indecisive, such as the rules of the Health protocol where there are still many people who are negligent and don't even care about the threat to their safety. Until covid19 but the spread is high.

The aid policy to the community seems to be only temporary and not carefully calculated, such as basic food assistance that comes only twice, after that it disappears, and the most ironic thing is that the aid was mistargeted, even many who should not be entitled to receive it. 


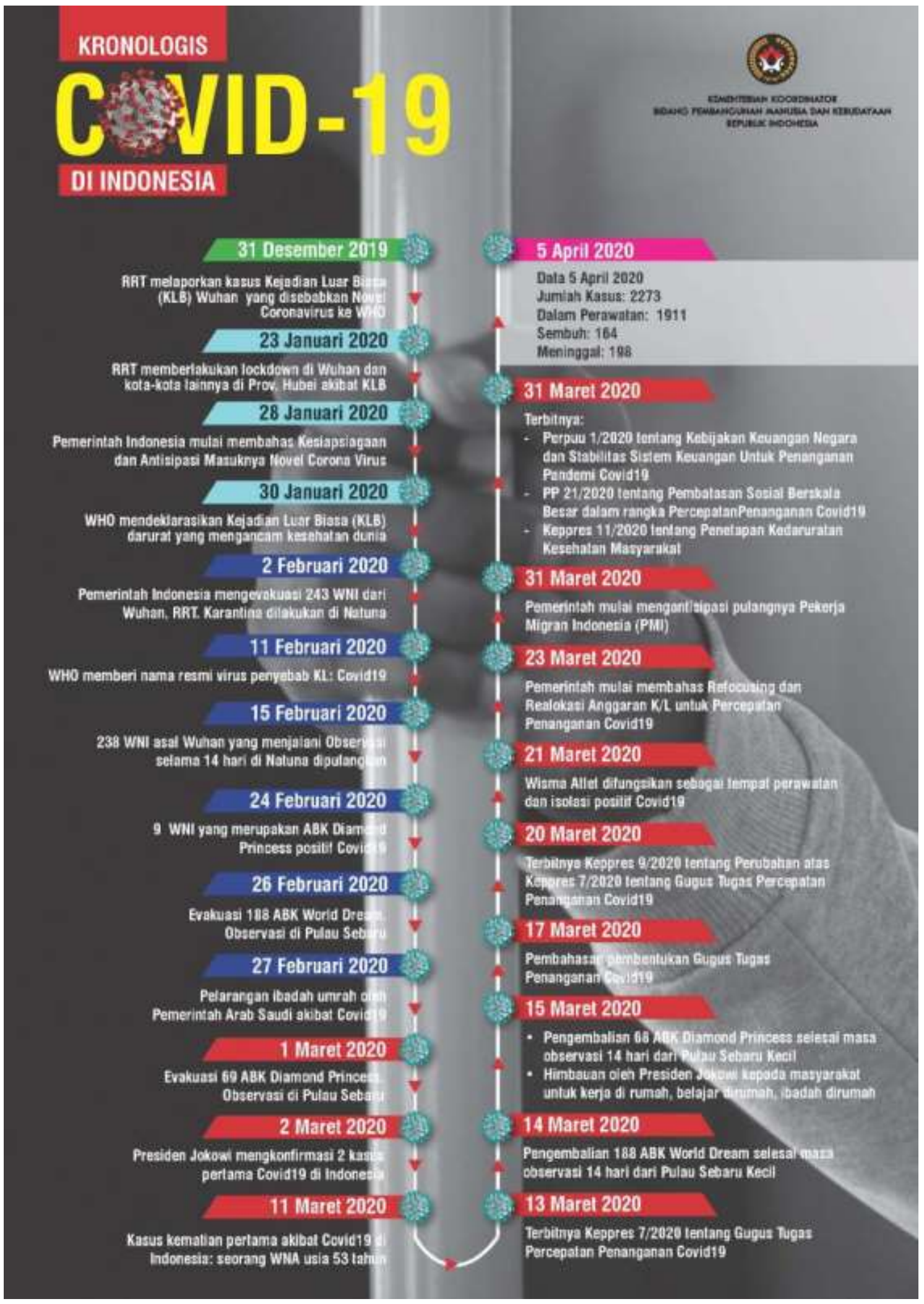

Source: Ministry of Technology and Information Technology 2020

Not to mention the aid is not in accordance with the nominal that has been determined by the government, many products suddenly appear. No wonder this aid smelled fishy from the start, it was proven that the social minister was arrested by the KPK because of this case of basic food assistance. 
Vaccination has been running but the quantitative is still low compared to our population so that vaccination has not been able to run optimally. Vaccination should be absolute and mandatory because it is the solution so that we get out of this humanitarian disaster, what happens if a lecturer is required to be vaccinated before teaching but the students are not required to increase the effectiveness of reducing this epidemic, the government should use all available resources so that all people can To get this vaccine, of course, even if the government does not have a budget, of course the vaccination is in accordance with the social class in the community. The government data bank has it and may be accurate from RT/RW to the province to have it, so if it is not resolved immediately, it is likely that Indonesia is the country that has taken the longest to overcome this covid19 the government should be very firm, for example, if someone refuses not to apply the applicable law regarding health protocols.

The pre-employment card program, which has been running for several waves, seems to be merely painting on water by providing assistance with the condition that following the training 3 times the training will immediately get a certificate and the hard skill results that the government hopes will not be achieved.

Assistance for SMEs whose main purpose is to increase production capacity and market share is not effective because some SMEs who receive it do not use it properly and some are even used to buy consumer goods.

\section{Perkembangan Biaya Penanganan Covid-19 APBN 2020}

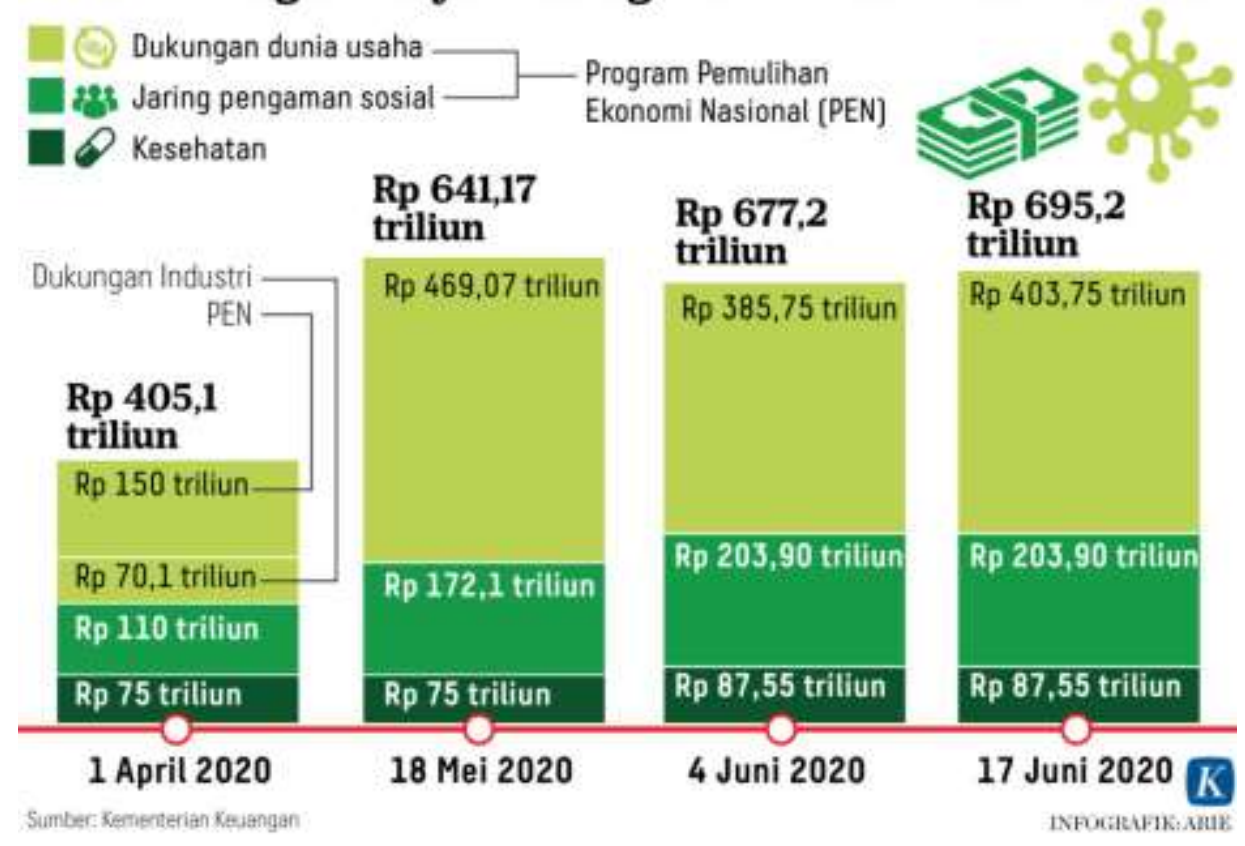

Source : www.kompas.com, 2020

In the midst of an economic downturn with low economic growth, a high current account deficit and a widening budget deficit. The government is charged with the budget for handling this epidemic. budget allocations will be disrupted because resources will be sucked into this epidemic. so that the economic multiplayer of the 2020/2021 budget will not have a significant impact on the national economy. So the government must make the right policies, not only focusing on macro policies but more emphasis on micro economic policies because this is the solution. So far, our economic policies have been seen as beacon, such as creating a 35,000 Mega Watt power plant program, constructing a $1000 \mathrm{~km}$ Toll Road, the Sea Toll Road in theory is fantastic but in practice it 
is very difficult because the law of supply and demand will apply. So the policy must adjust the existing market position and it has been proven that up to now it has not been realized.

Humans were created to be greedy and humans are creatures who are always dissatisfied with what they have, maybe why the angel protested when Allah would create humans, and it is proven today. In the midst of this humanitarian disaster, there are many who take advantage of opportunities to make profits, such as hoarding groceries, stockpiling health products, corruption in congregation with government assistance and what is very sad is the use of used medical equipment for handling COVID-19, besides being immoral, it also feels more cruel than devil. It is proven that the minister of social affairs was involved in the corruption of social services with several of his subordinates and third parties who received the procurement project, but the news is that there has been no follow-up. People hope that many regulations made by the government at least reduce the basic burden of society to survive.

Of course, we hope that this corruption case of social assistance will be opened to the public and that the money from this corruption will flow to anyone. maybe there are many more corruption cases regarding this government aid, it's just that it is not revealed and it's possible that the money from corruption goes to political parties, if we calculate the budget for handling this epidemic, it's close to Rp. 700 trillion, if for example, $10 \%$ of the money leaks out. The missing country is Rp. 70 trillion, what a fantastic value if we buy a fast SU35 BM fighter, of course the TNI will get approximately 30 sophisticated fighter planes equivalent to the F35 A that can replace the fast F5 Tiger which is very old and must be replaced as soon as possible. Of course, there is great hope for the KPK and BPK as the spearheads in saving state money.

Corruption is increasingly rampant despite the difficult state of the country, this is proven by cases handled by the KPK which have dragged many government officials from the Minister, governors, regents to members of the DPRRI and DPRD. So that the existence of the Corruption Eradication Commission does not make corruption decrease, it seems that it is willing to run rampant. One of the reasons is the high political costs in the country to nominate a regent, it costs billions of dollars for campaign operations so that candidates for regional heads seek sponsors to support the costs of their candidacy in exchange for being promised development projects. The KPK, which is the final foundation of society, is now starting to dim, not having fangs like The previous years were not without reason, this was due to the many laws that were revised by the KPK which reduced the space for the KPK to move. The KPK is a commission that has a certain time limit but in the midst of high corruption in Indonesia, it still needs the KPK. 


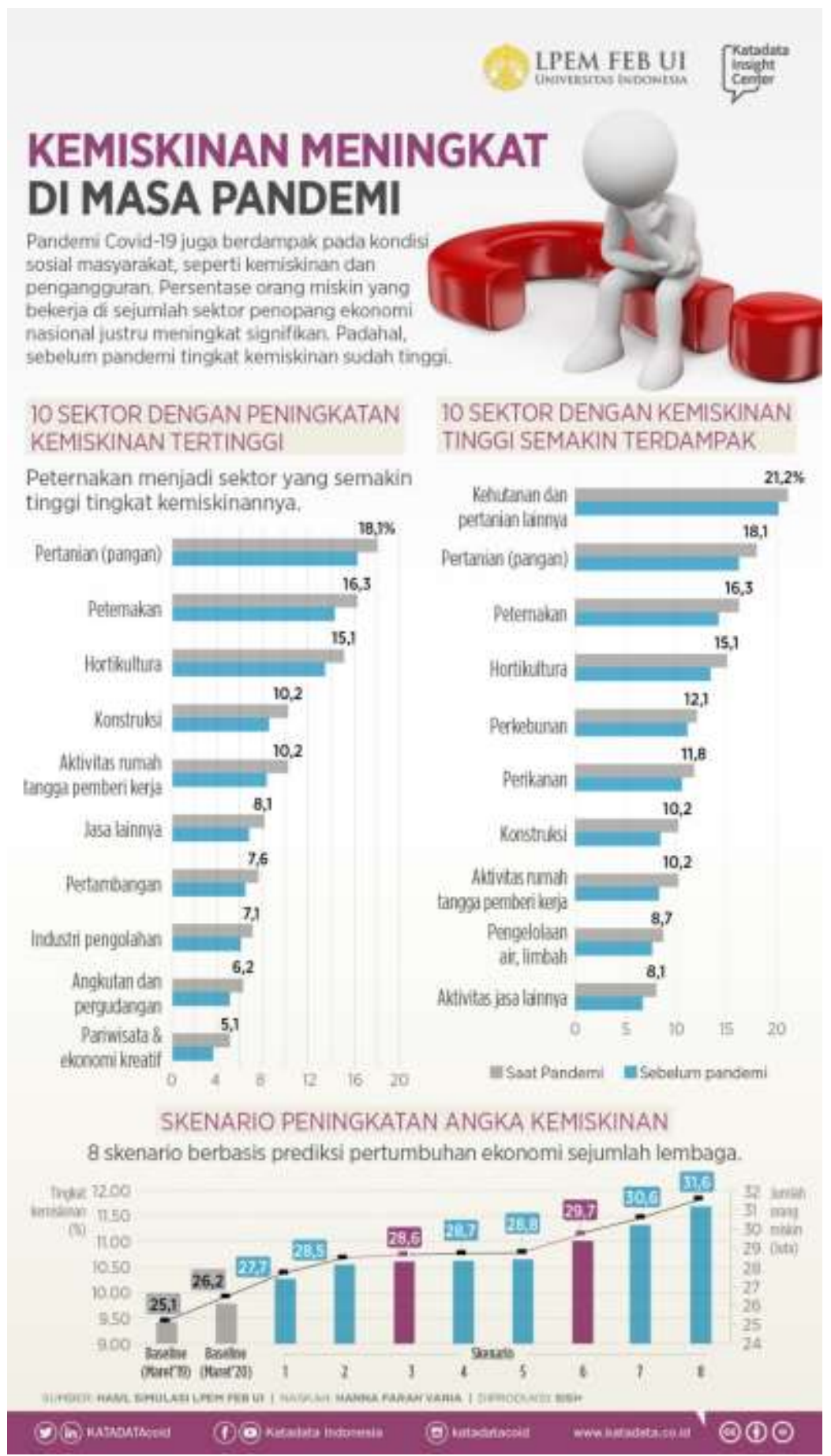

Source : Kata Data LP3M FEB UI 2020

People are getting bored with the situation for the past two years in the midst of a humanitarian disaster that has not yet recovered, a sluggish economic situation that has made people's purchasing power fall. The long-term impact of Covid-19 is the problem of poverty and crime, the increase in the unemployment rate will correlate with the increase in poverty which will ultimately increase the crime rate. So that government regulations or policies must be mature and should not be prepared for a moment because the wrong policy will be fatal. Communication, coordination in the cabinet must be in the same direction or with one vision, don't blame each other because people don't see the minister, but see the president. The inter-departmental interdepartmental interests must be eliminated, those that are cross-sectoral. 


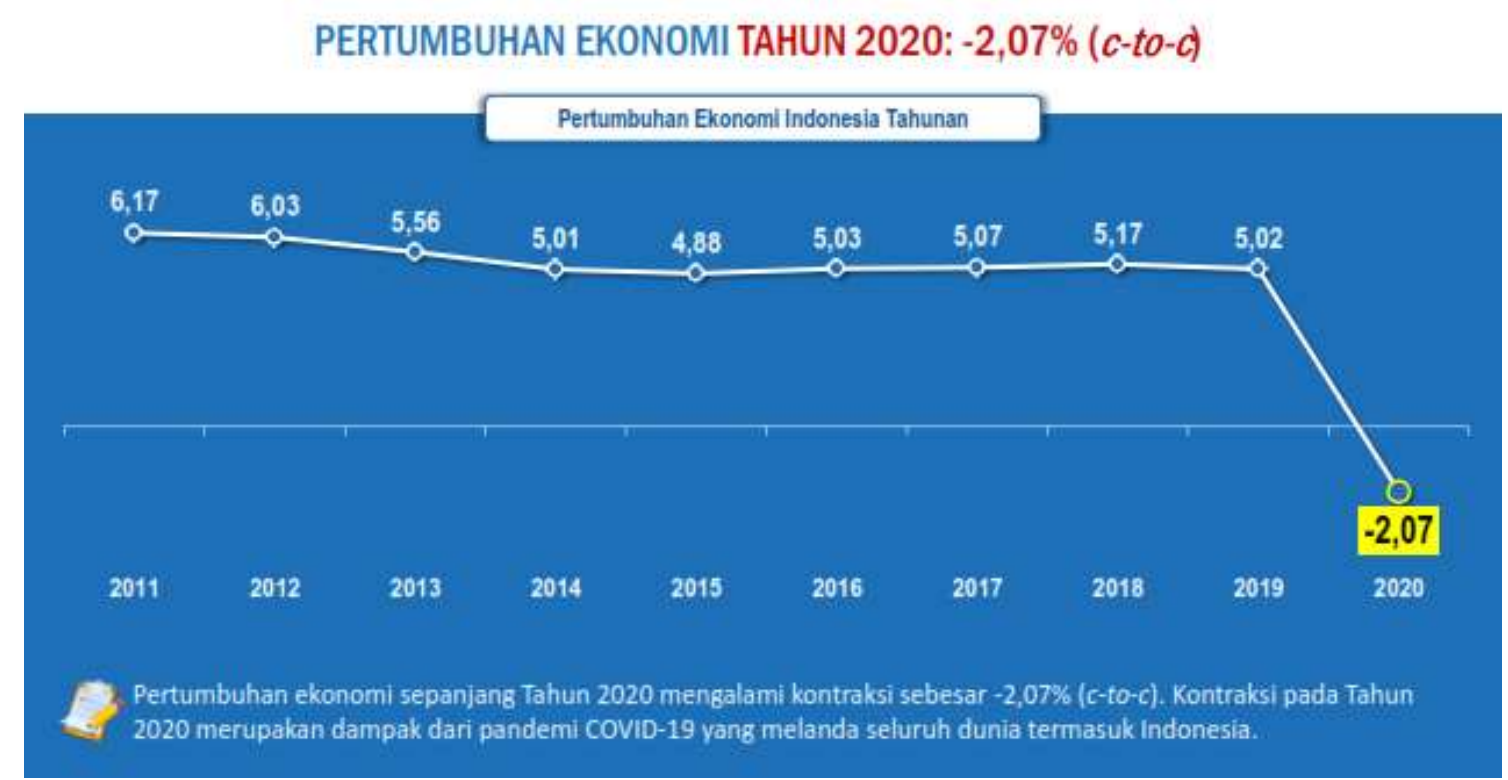

Surce : Studiekonomi.com, 2020

Closing: Life must go on regardless of the circumstances and in any way because basically humans are caliphs or representatives on this earth, despair, complaining or blaming the government is not a solution because the state has limitations even though it has been stipulated by law regarding the safety, security, welfare of its people. We hope that this Covid19 will soon disappear on this earth and return to the old order. Although it will take a long time but we must patiently wait for it.

Social justice for all Indonesian people, the fifth principle of Pancasila, which is the great aspiration of this nation, although until now it is still far from expectations. Poverty, Ignorance, Unemployment, Corruption, Drugs are the biggest enemies of this nation, so that whoever becomes the president will be a tough task.

\section{"Long live Greater Indonesia"}

